\title{
PENGEMBANGAN BAHAN AJAR BERBASIS MASALAH PADA MATA KULIAH MATEMATIKA EKONOMI PROGRAM STUDI PENDIDIKAN MATEMATIKA
}

\author{
Rina Agustina ${ }^{1)}$, Ira Vahlia ${ }^{2)}$ \\ ${ }^{1), 2)}$ Pendidikan Matematika FKIP Universitas Muhammadiyah Metro \\ E-mail: aasyiqun1212@ gmail.com ${ }^{1)}$,iravahlia768@yahoo.co.id ${ }^{2)}$
}

\begin{abstract}
Teaching materials are needed for students to support the lecture. The purpose of this study was to determine how to develop problem-based teaching materials on the subjects of mathematical economics mathematics education courses. This research was conducted at the University of Muhammadiyah Metro by selecting a student of mathematics education as a research subject.This study is a research development. The method used as follows: (1) research and information gathering, (2) planning, (3) product development, (4) the initial trials, (5) product revision, (6) the field trials, (7) the revised product field trials, (8) the operational testing of products, (9) the revision of the product and (10) the implementation and dissemination. To obtain problem-based teaching materials will be validated teaching materials by 2 experts math education materials and one person linguists. The achievement of this research is problem-based teaching materials that can support economic mathematics lectures. The achievement that will be produced is $\geq 50 \%$ students of mathematics education are getting the optimal learning course on the math economy. Based on the results of questionnaires percentage obtained validation criteria of $80 \%$ of teaching materials and meet the criteria are valid for.
\end{abstract}

Keywords: teaching material, problem solving, economic math

\section{PENDAHULUAN}

Program studi pendidikan matematika merupakan salah satu program studi yang banyak diminati mahasiswa ketika akan masuk perguruan tinggi. Salah satu yang menjadi minat masyarakat pada program studi pendidikan matematika adalah peluang yang lebih besar untuk mendapatkan pekerjaan setelah selesai menumpuh pendidikan sarjana. Pada program studi pendidikan matematika, mahasiswa tidak hanya diberi pengetahuan pembelajaran untuk menjadi seorang guru, tetapi juga diberi pengetahuan agar dapat mengaplikasikan ilmu matematika pada kehidupan sehari-hari. Salah satu mata kuliah yang mengajarkan matematika dalam kehidupan sehari-hari adalah mata kuliah matematika ekonomi.

Pada mata kuliah matematika ekonomi, mahasiswa diberi pengetahuan terkait dengan menghitung besarnya jumlah penduduk, pertumbuhan penduduk, besarnya suku bunga, dan lain sebagainya. Dengan adanya mata kuliah matematika ekonomi, mahasiswa diharapkan dapat mengaplikasikan materi-materi matematika yang telah didapat pada masalah kehidupan sehari-hari. Dalam proses perkuliahan, sangat dibutuhkan 
sarana penunjang yang baik agar proses perkuliahan dapat optimal. Salah satu sarana penunjang yang dibutuhkan adalah adanya bahan ajar yang digunakan secara jelas oleh dosen pengajar.

Untuk menunjang proses perkuliahan matematika ekonomi dibutuhkan bahan ajar yang memuat masalah-masalah kehidupan sehari-hari yang dapat diselesaikan dengan menggunakan materi matematika. Selama ini, pada program studi pendidikan matematika belum ada bahan ajar yang digunakan secara khusus oleh dosen untuk menunjang proses perkuliahan matematika ekonomi. Dalam proses perkuliahan, mahasiswa masih dibebaskan untuk menggunakan bahan ajar yang bersumber dari mana saja. Sedangkan dalam proses perkuliahan, mahasiswa sangat membutuhkan bahan ajar yang memang digunakan secara khusus oleh dosen pengampu.

Bahan ajar matematika ekonomi haruslah bahan ajar yang banyak memuat masalah dalam kehidupan sehari-hari. Bahan ajar ini merupakan bahan ajar yang berbasis masalah sehingga dapat membantu mahasiswa agar dapat berpikir lebih kritis dan optimal selama proses perkuliahan. Dengan adanya bahan ajar ini diharapkan dapat menunjang proses perkuliahan matematika ekonomi.

Berdasarkan hasil penelitian Husniyah (2013), didapatkan bahwa salah satu keunggulan bahan ajar berbasis masalah adalah dapat sesuai dengan karakteritik siswa. Selain itu, bahan ajar berbasis masalah dapat memudahkan mahasiswa dalam mempelajari materi sehingga dapat membantu mengembangkan kemampuan berpikir mahasiswa. Selama ini, bahan ajar yang digunakan dalam perkuliahan matematika ekonomi adalah bahan ajar yang berbasis umum. Bahan ajar ini sulit dipahami mahasiswa dikarenakan tidak focus pada masalah yang sebenarnya di kehidupan sehari-hari. Sehingga sangat diperlukan adanya bahan ajar berbasis masalah pada mata kuliah matematika ekonomi bagi mahasiswa program studi pendidikan matematika agar capaian perkuliahan lebih optimal.

Menurut Bock dalam "Getting It Right : R\&D Methods in Science and Engineering" dalam bukunya Putra (2012: 68) menjelaskan pengertian pengembangan: "Development is a process that applies knowledge to create new device on effects".

Menurut Trianto (2010: 189) "model pengembangan 4-D tahap utama yaitu Define, Design, Develop, dan Disseminate atau diadaptasikan menjadi model 4-P, yaitu pendefinisian, perancangan, pengembangan, dan penyebaran".

Sriraman (2010:

menyatakan bahwa " dalam proses pembelajaran siswa dapat memecahkan masalah dengan diberi kesempatan untuk menghadapi situasi realitas dalam kehidupan sehari-hari. Dengan model pembelajaran problem solving, siswa dapat menggeneralisasi dan mendapatkan solusi dari permasalahan."

Dari beberapa pendapat diatas berbasis masalah merupakan rangkaian tindakan yang digunakan untuk menyelesaikan masalah dalam mencapai tujuan pembelajaran sehingga dapat membantu mengatasi masalah yang sedang dihadapi mahasiswa. Pengembangan bahan ajar berbasis masalah yaitu pengembangan bahan ajar yang digunakan untuk memfasilitasi pencapaian kemampuan belajar mahasiswa terutama mata kuliah matematika ekonomi yang 
didalamnya terdapat permasalahan dalam kehidupan nyata.

\section{METODE PENELITIAN}

\section{Tahapan-Tahapan Penelitian}

Menurut Borg dan Gall (dalam Suwahono, 2012: 153) "prosedur yang ditempuh dalam pengembangan di bidang pendidikan ini memiliki dua tujuan utama, yaitu: (1) mengembangkan produk dan (2) menguji keefektifan produk. Fungsi pertama merupakan pengembangan sedangkan fungsi kedua merupakan validasi."

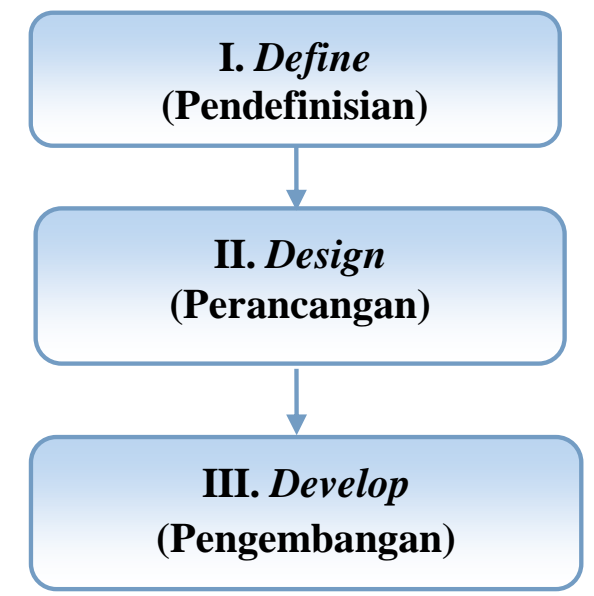

Gambar 1. Skema Tahapan - Tahapan Penelitian

Tahap I: Define (Pendefinisian)

Tahap define merupakan tahap untuk menetapkan dan mendefinisikan syarat-syarat yang dibutuhkan dalam pengembangan pembelajaran. Penetapan syarat-syarat yang dibutuhkan dilakukan dengan memperhatikan serta menyesuaikan kebutuhan pembelajaran untuk mahasiswa matematika. Tahap define mencakup lima langkah pokok, yaitu analisis ujung depan (front-end analysis), analisis peserta didik (learner analysis), analisis konsep (concept analysis), analisis tugas (task analysis) dan perumusan tujuan pembelajaran (specifying instructional objectives).

Tahap II: Design (Perancangan)

Tahap perancangan bertujuan untuk merancang perangkat pembelajaran. Menurut Trianto (2010: 191) ada Empat langkah yang harus dilakukan pada tahap ini, yaitu:(1) penyusunan standar tes (criterion-test construction), (2) pemilihan media (media selection) yang sesuai dengan karakteristik materi dan tujuan pembelajaran, (3) pemilihan format (format selection), yakni mengkaji format-format bahan ajar yang ada dan menetapkan format bahan ajar yang akan dikembangkan, dan (4) membuat rancangan awal (initial design) sesuai format yang dipilih.

Tahap III: Develop (Pengembangan)

Tahap pengembangan adalah tahap untuk menghasilkan produk pengembangan yang dilakukan melalui dua langkah, yakni: (1) penilaian ahli (expert appraisal) yang diikuti dengan revisi, (2) uji coba pengembangan (developmental testing).

\section{Lokasi Penelitian}

Penelitian dilaksanakan di Universitas Muhammadiyah Metro Propinsi Lampung dan subjek penelitian adalah mahasiswa semester 6 yang terdiri dari 2 kelas. Kelas A untuk 2 kelompok besar. Masing-masing kelompok besar terdiri dari 10 mahasiswa. Kelas B untuk 2 kelompok kecil. Masing-masing kelompok kecil terdiri dari 5 mahasiswa yang mengambil mata kuliah matematika ekonomi.

\section{Peubah yang Diamati/Diukur,}

Dalam penelitian ini, peubah yang diamati adalah bahan ajar 
berbasis masalah pada mata kuliah matematika ekonomi program studi pendidikan matematika.

\section{Model Yang Digunakan}

Jenis penelitian ini adalah penelitian pengembangan (Research and Development) yaitu jenis penelitian yang mengembangkan suatu produk baru atau menyempurnakan produk yang telah ada sebelumnya. Penelitian pengembangan ini mengacu pada model pengembangan bahan ajar 4-D (four-D Model) yang terdiri dari empat tahapan yaitu tahap pendefinisian (define), tahap perancangan (design), tahap pengembangan(develop), dan tahap penyebaran (disseminate). Model pengembangan 4-D digunakan peneliti karena tahapan penelitian pengembangan 4- D memiliki kelebihan, yaitu dalam model 4-D melibatkan analisis materi dan analisis tugas dalam menentukan tujuan pembelajaran khusus, sehingga akan memudahkan dalam menjabarkan tujuan pembelajaran umum ke tujuan pembelajaran khusus. Model pengembangan ini sudah terfokus pada pengembangan bahan ajar. Pada penelitian ini hanya sampai pada tahap pengembangan (develop).

\section{Rancangan Penelitian}

Penelitian pengembangan meliputi : 1) penelitian dan pengumpulan informasi, 2) perencanaan, 3) pengembangan produk, 4) uji coba awal, 5) revisi produk, 6) uji coba lapangan, 7) revisi produk uji coba lapangan, 8) uji coba operasional produk, 9) revisi produk dan 10) implementasi dan desiminasi. Semua langkah diatas akan dicakup dalam pengembangan produk dan validasi produk yang mengacu pada pendapat Borg \& Gall pada penelitian ini cukup menggunakan langkah 1 sampai 7 yang juga sudah diadaptasi sesuai dengan keperluan penelitian ini. Dari skema pengembahan bahan ajar, saat ini bahan ajar sudah pada tahap hasil validasi ahli.

\section{Teknik Pengumpulan Data}

Data dalam penelitian ini adalah informasi tentang efektivitas bahan ajar berbasis masalah yang di dapat dari angket respon mahasiswa. Berikut langkah-langkah untuk mendapatkan data penelitian:

a. Menyiapkan bahan ajar

b. Memvalidasi bahan ajar. Bahan ajar akan divalidasi oleh 3 orang validator.

c. Merevisi bahan ajar yang didapat dari validator.

d. Menguji coba bahan ajar kepada mahasiswa.

e. Memberikan angket respon mahasiswa.

f. Merivisi bahan ajar berdasarkan hasil angket mahasiswa.

g. Mencetak bahan ajar.

i. Teknik pengumpulan data yang telah dilaksanakan pada tahap ini telah sampai pada langkah 3 dan didapatkan bahan ajar yang valid dari para ahli.

\section{Analisis Data}

Tahap ini dilaksanakan setelah didapatkan data dari angket yang diisi oleh 3 validator yang terdiri dari 2 ahli materi matematika dan 1 ahli bahasa.

Tabel 1 Kriteria Jawaban Item Instrumen Validasi Beserta Skornya

\begin{tabular}{|c|c|c|}
\hline No & Jawaban & Skor \\
\hline 1 & Sangat baik & 4 \\
\hline 2 & Cukup baik & 3 \\
\hline 3 & Kurang baik & 2 \\
\hline 4 & Tidak baik & 1 \\
\hline
\end{tabular}


Kemudian data dianalisis secara deskriptif kuantitatif, yaitu menghitung persentase skor bahan ajar yang dikembangkan

Persentase Skor $=\frac{\text { Jumlah Skor per indikator }}{\text { Jumlah Skor Maks.Indikator }} \times 100 \%$

Dari hasil perhitungan

Tabel 2 Kriteria Persentase Indikator Bahan Ajar (dalam Sibuea, 2013: 6)

\begin{tabular}{|l|c|}
\hline \multicolumn{1}{|c|}{ Kriteria Validitas } & Tingkat Validitas \\
\hline $\begin{array}{l}\text { Sangat valid, atau dapat digunakan tanpa } \\
\text { revisi }\end{array}$ & $85 \%<\mathrm{X} \leq 100 \%$ \\
\hline $\begin{array}{l}\text { Cukup valid, atau dapat digunakan dengan } \\
\text { revisi kecil }\end{array}$ & $70 \%<\mathrm{X} \leq 85 \%$ \\
\hline $\begin{array}{l}\text { Kurang valid, disarankan tidak } \\
\text { dipergunakan karena perlu revisi besar }\end{array}$ & $50 \%<\mathrm{X} \leq 70 \%$ \\
\hline Tidak valid, atau tidak boleh dipergunakan & $0 \%<\mathrm{X} \leq 50 \%$ \\
\hline
\end{tabular}

Bahan ajar dikatakan baik dan layak digunakan jika dinyatakan valid oleh validator dengan rata rata kriteria minimal“Cukup Valid". Berdasarkan hasil validasi dari angket didapatkan kriteria persentase bahan ajar sebesar $80 \%$ dan masuk dalam kriteria cukup valid.

\section{Indikator Capaian Hasil \\ Penelitian}

Indikator capaian hasil penelitian ini adalah:

a. Bahan ajar berbasis masalah dapat menunjang pembelajaran mahasiswa pada mata kuliah matematika ekonomi.

b. Mahasiswa yang mendapatkan hasil belajar optimal dengan menggunakan bahan ajar berbasis masalah mencapai $\geq 50 \%$. menggunakan rumus di atas, dihasilkan angka dalam bentuk persen. Klasifikasi skor tersebut kemudian ditafsir dengan kalimat bersifat kualitatif yang tercantum dalam Tabel 2 .

\section{HASIL PENELITIAN DAN PEMBAHASAN}

Pengembangan bahan ajar dimulai pada tanggal 1 Agustus 2016 dengan cara menyebar angket kepada mahasiswa yang pernah mengikuti perkuliahan matematika ekonomi. Angket ini berisi tentang kondisi bahan ajar yang digunakan dalam perkuliahan dan efektifitas dari penggunaan bahan ajar tersebut. Dari penyebaran angket tersebut, ketua dan anggota melakukan koordinasi pada tanggal 3 Agustus 2016 untuk melakukan analisis hasil angket mahasiswa. Berdasarkan hasil angket tersebut, didapatkan data informasi bahwa bahan ajar yang digunakan kurang memadai dan membantu mahasiswa dalam pembelajaran. Hal ini dapat dilihat pada sampel hasil angket mahasiswa pada Gambar 2.

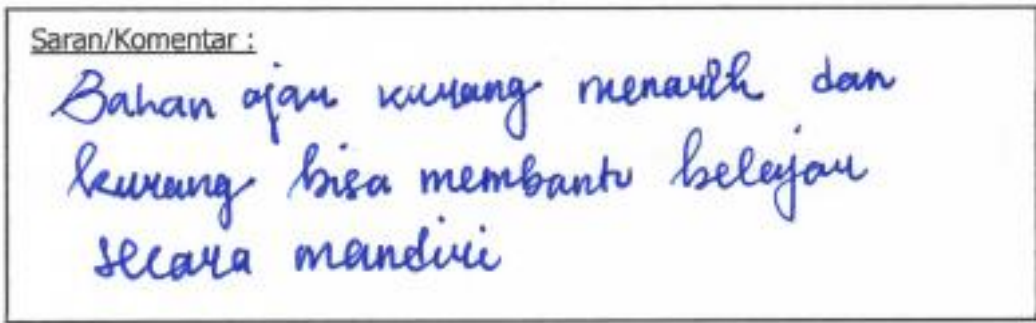

Gambar 2. Sampel Hasil Angket Mahasiswa 
Setelah dilakukan penyebaran angket, langkah selanjutnya melakukan validasi bahan ajar. Bahan ajar tersebut divalidasi oleh: (1) Bapak Swadiyta Rizki, M. Sc Ketua Program Studi Pendidikan Matematika Universitas Muhammadiyah Metro, (2) Ibu Dra. Sutrisni Andayani, M. Pd. Dosen Pendidikan Matematika Universitas Muhammadiyah Metro yang sedang menempuh studi S3 pada Universitas Negeri Jakarta, dan (3) Ibu Siti Khoiriyah, M. Pd. Dosen Pendidikan Matematika STKIP Muhammadiyah Pringsewu.

Pada tanggal 5 Agustus 2016, bahan ajar telah selesai divalidasi. Berdasarkan hasil validasi didapatkan, data berikut:

Tabel 3 Nilai Hasil Validasi Bahan Ajar

\begin{tabular}{|l|l|c|c|}
\hline No & \multicolumn{1}{|c|}{ Nama } & Nilai & Kategori \\
\hline 1. & Dra. Sutrisni Andayani. M.Pd. & $90 \%$ & Sangat Valid \\
\hline 2. & Swaditya Rizki, M. Pd. & $82 \%$ & Cukup Valid \\
\hline 3. & Siti Khoiriyah, M. Pd. & $90 \%$ & Sangat Valid \\
\hline \multicolumn{2}{|c|}{ RATA-RATA } & $\mathbf{8 7 \%}$ & Sangat Valid \\
\hline
\end{tabular}

Dari Tabel 3, dapat terlihat bahwa nilai validasi bahan ajar yang diperoleh dari validator 1 sebesar $90 \%$, validator 2 sebesar $82 \%$, dan validator 3 sebesar $90 \%$. Sehingga berdasarkan nilai dari 3 validator tersebut, dapat diambila rata-rata nilai validasi bahan ajar sebesar $87 \%$ dan memenuhi kriteria sangat valid. Dari hasil validasi tersebut, maka bahan ajar berbasis masalah ini telah siap untuk di gunakan dan diuji coba pada mahasiswa dalam perkuliahan matematika ekonomi.
Penggunaan bahan ajar berbasis masalah ini di mulai pada hari Senin, tanggal 10 September 2016 pada materi aplikasi diferensial dalam bidang ekonomi. Dari hasil uji coba kelompok kecil yang pertama ini didapatkan data bahwa ada materi yang kurang lengkap pada bahan ajar. Pada materi elastisitas, terdapat kekurangan tentang grafik fungsi elastisitas. Sehingga pada bahan ajar, akan ditambahkan materi grafik fungsi elastisitas. Berikut sampel saran dari mahasiwa pada uji kelompok kecil pertama.

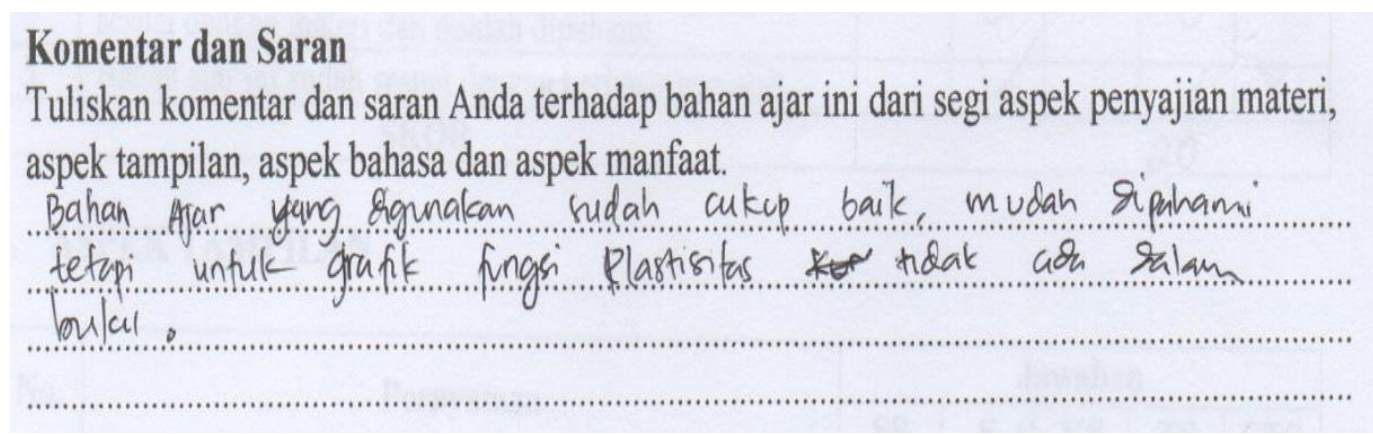

Gambar 3 Komentar dan saran mahasiswa pada uji kelompok kecil pertama

Setelah analisis dan revisi hasil uji kelompok kecil pertama, maka dilakukan uji kelompok kecil kedua pada hari Selasa, 20 September 2016. Dari hasil uji ini, didapatkan komentar dan saran bahwa bahan ajar ini dapat meningkatkan keaktifan belajar mahasiswa. Komentar ini dapat dilihat pada Gambar 4. 
e-ISSN 2442-5419 Vol. 5, No. 2 (2016) 152-160

p-ISSN 2089-8703

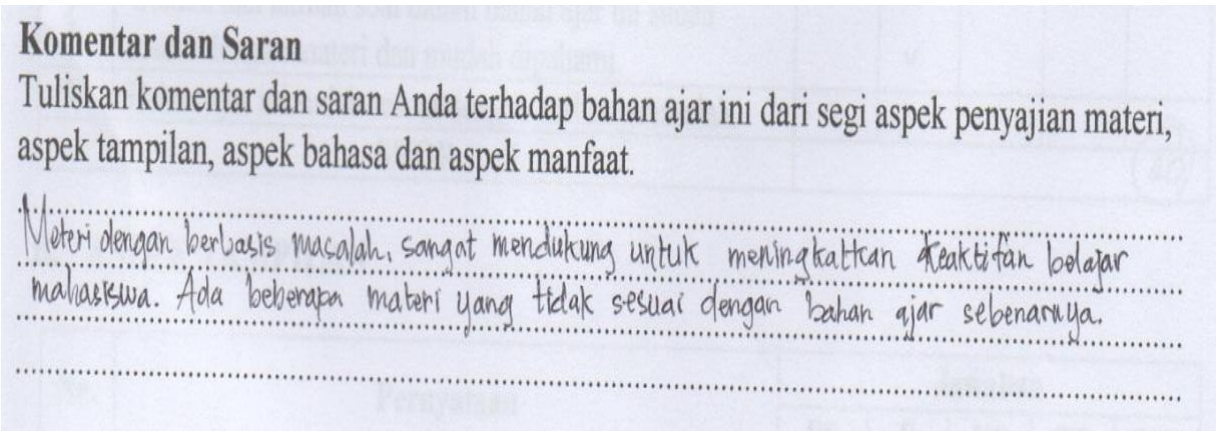

Gambar 4 Komentar dan saran mahasiswa pada uji kelompok kecil kedua

Setelah dilakukan dua kali uji kelompok kecil, maka langkah selanjutnya melaksanakan uji bahan ajar berbasis masalah pada kelompok besar. Uji kelompok besar yang pertama dilakukan pada hari Selasa tanggal 27 September 2016. Dari uji kelompok besar ini, didapatkan saran seperti pada gambar 5 .

\section{Komentar dan Saran \\ Tuliskan komentar dan saran Anda terhadap bahan ajar ini dari segi aspek penyajian materi, aspek tampilan, aspek bahasa dan aspek manfaat. penyajon mater sudah cokup loile tamplan yang menarik bahasa
uang di gunakan sudah balcu}

Gambar 5 Komentar dan saran mahasiswa pada uji kelompok besar pertama

Setelah analisis dan revisi hasil uji kelompok besar pertama, maka dilakukan uji kelompok kecil kedua pada hari Selasa, 8 Oktober 2016. Dari hasil uji ini, didapatkan komentar dan saran bahwa bahan ajar berbasis masalah ini dapat bermanfaar bagi mahasiswa agar menjadi lebih rajin dalam mengerjakan latihan-latihan soal. Komentar ini dapat dilihat pada Gambar 6.

\section{Komentar dan Saran \\ Tuliskan komentar dan saran Anda terhadap bahan ajar ini dari segi aspek penyajian materi, aspek tampilan, aspek bahasa dan aspek manfaat.

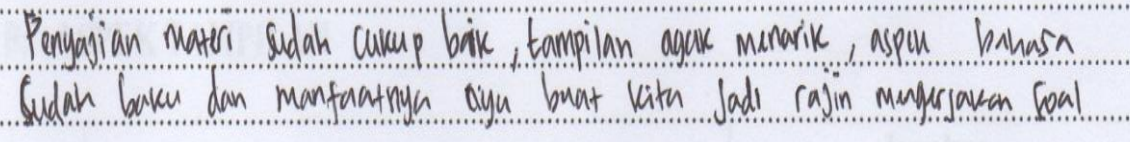

Gambar 6 Komentar dan saran mahasiswa pada uji kelompok besar kedua 
Setelah melakukan uji kelompok besar yang kedua, maka langkah selanjutnya adalah menguji efektivitas penggunaan bahan ajar ini. Untuk pengujian efektivitas bahan ajar berbasis masalah ini menggunakan kelas A sebagai kelas eksperimen yang terdiri dari 41 orang mahasiswa. Sedangkan yang menjadi kelas kontrol adalah kelas $\mathrm{B}$ yang terdiri dari 31 orang mahasiswa. Sebelum dilakukan uji tes soal, terlebih dahulu mahasiwa pada kelas A diberikan angket evaluasi dari penggunaan bahan ajar berbasis masalah. Dari angket mahasiswa ini didapatkan persentase sebesar 74,6\% dan memenuhi kriteria cukup valid dengan revisi kecil. Berikut Tabel nilai rata-rata dari penggunaan bahan ajar berbasis masalah.

Tabel 4 Nilai rata-rata mahasiswa pada penggunaan bahan ajar berbasis masalah

\begin{tabular}{|c|c|}
\hline Kelas & Nilai Rata-Rata \\
\hline A (Kelas Eksperimen) & 66,85 \\
\hline B (Kelas Kontrol) & 63,45 \\
\hline
\end{tabular}

Tabel 5 Hasil Uji Efektivitas Penggunaan Bahan Ajar

\begin{tabular}{|l|c|c|}
\hline Kelas & Kelas B & Kelas A \\
\hline Jumlah & & 41 \\
\hline $\mathrm{N}$ & 31 & 66,85 \\
\hline $\mathrm{X}$ & 63,45 & 434,72 \\
\hline Varians & 408,72 & 20,85 \\
\hline Standar deviasi & 20,21 & \\
\hline
\end{tabular}

Ket:

t hit $=18,2527$

$\mathrm{t}$ tabel $=0,1499$

Karena $\mathrm{t}$ hitung $>\mathrm{t}$ tabel maka Ho ditolak dapat disimpulkan bahwa terjadi perbedaan rata-rata hasil belajar kelas yang menggunakan bahan ajar matematika ekonomi berbasis masalah. Dari tabel tersebut, dapat terlihat bahwa kelas A sebagai kelas eksperimen memiliki nilai rata-rata sebesar 66,85 yang lebih tinggi dibandingkan kelas B yang memiliki rata-rata sebesar 63,45.

\section{KESIMPULAN DAN SARAN}

Dari hasil penggunaan bahan ajar berbasis masalah didapatkan, bahwa:

1. Nilai rata-rata hasil belajar mahasiswa sebesar 66,85.

2. Presentase angket respon mahasiswa sebesar 74,6 \% yang memenuhi kriteria cukup valid.

Dari hasil penelitian yang diperoleh, maka peneliti memberikan saran kepada peneliti lain yang ingin menggunakan bahan ajar ini, agar mengembangkan bahan ajar menjadi bahan ajar berISBN.

\section{DAFTAR PUSTAKA}

Husniyah, Ahfidatul. 2013. Pengembangan Bahan Ajar Berbasis Masalah Untuk Meningkatkan Kemampuan Berpikir Kritis Fisika Siswa Kelas XI IPA MAN 3 Malang. Universitas Negeri Malang. (Skripsi tidak diterbitkan)

Putra, Nusa. 2012. Research \& Development Penelitian dan Pengembangan. Jakarta: Raja Gravindo Persada. 
e-ISSN 2442-5419 Vol. 5, No. 2 (2016) 152-160

p-ISSN 2089-8703

Trianto. 2010. Mendesain Model Pembelajaran Inovatif-Progresif. Jakarta: Kencana Prenada Media Group.

Sibuea, Ris Irawati. 2013. Pengembangan Bahan Ajar Matematika melalui Pendekatan Matematika Realistik Berbasis Kurikulum 2013 untuk Meningkatkan Kemampuan Komunikasi Matematis Siswa di Kelas VIII SMP Tri Jaya Medan. Paradikma Jurnal Pendidikan Matematika. Vol. 6, No.2. Hal 110

Sriraman, B. 2010. Conjecturing via reconceived classical analogy. Columbia. J. of Educational Studies in Mathematics. Vol 76 (No. 2): 123-140.

Suwahono. 2012. Pengembangan Sistem Penilaian Keterampilan Matematika”.. $\quad$ Yogyakarta: Progam Pascasarjana UNY. (Disertasi Tidak Diterbitkan. 